\title{
A PROBLEMATIZAÇÃO NO PROCESSO ENSINO-APRENDIZAGEM DA COMUNICAÇÃO'
}

\author{
PROBLEM SOLVING IN THE TEACHING-LEARNING PROCESS OF \\ COMMUNICATION \\ LA PROBLEMATIZACIÓN EN EL PROCESO ENSEÑANZA-APRENDIZAJE \\ DE LA COMUNICACIÓN
}

\author{
Mariluci Alves Maftum² \\ Verônica Azevedo Mazza ${ }^{3}$ \\ Maguida Costa Stefanelli ${ }^{4}$
}

RESUMO: Trata-se de um relato de experiência, de ensino-aprendizagem de comunicação, sustentada na problematização, desenvolvida com alunos do nivel Técnico em Enfermagem de Curitiba. Os resultados corroboram a proposta de Stefanelli, do processo de ensino-aprendizagem dos conteúdos de comunicação humana e terapêutica. As estratégias de comunicação terapêutica facilitam tanto a compreensão dos alunos como também seu uso na relação com o paciente. O aprendizado se deu pelo fato de juntos, professor e aluno, compartilharem um único objetivo, a qualidade da assistência ao ser humano.

PALAVRAS-CHAVE: comunicação, educação, problematização

\section{INTRODUÇÃO}

A inquietante busca de formas de aprender e ensinar conteúdos de comunicação nos currículos de enfermagem com uma metodologia que propiciasse a apropriação desse conhecimento para sustentar a relação entre aluno e paciente levou as autoras a desenvolverem um trabalho com alunos de um Curso Técnico em Enfermagem de uma Escola Técnica da cidade de Curitiba. Para as autoras a comunicação é a base sustentadora de todas as relações humanas e sendo, como afirmam Bordenave (1982) e Stefanelli (1993), uma necessidade básica do ser humano, sem ela torna-se impossivel o existir enquanto pessoa que interage constantemente com o meio em que está inserido modificando-o e sendo por ela modificado.

Em se tratando de assistência de enfermagem não basta tão somente comunicar, mas sim, necessário fazê-lo de forma consciente, atentando para sua qualidade, o efeito do ato de se comunicar sobre as pessoas envolvidas, de modo a tornar a comunicação com o doente $e$ família uma forma de ajuda. Oferecer-Ihes mais que uma atenção compassiva e considerá-lo na sua condição de ser humano, que se encontra num momento de fragilização pela experiência da doença. Torna-se importante levá-lo à aceitação de sua condição de dependência em algum grau de modo que se sinta aceito, compreendido e ajudado para, como afirma Stefanelli (1993) e Travelbee (1979): modificar as coisas que possam ser modificadas e conviver com as que não

\footnotetext{
'Capítulo da Dissertação de Mestrado. Mestrado em Assistência de Enfermagem-UFSC/UFPR. ${ }^{2}$ Enfermeira. Mestre em Enfermagem. Docente do Curso Técnico em Enfermagem da ET/ UFPR.

${ }^{3}$ Enfermeira. Mestre em Enfermagem. Docente do Departamento de Enfermagem da UFPR. Membro do GEMA.

${ }^{4}$ Enfermeira. Doutor em Enfermagem. Professora titular visitante da UFPR. Orientadora.
} 
podem ser suprimidas, porém saindo dessa experiência mais fortalecido e com uma bagagem a mais de conhecimento.

Estas reflexões levaram as autoras a propor uma metodologia de ensino sistematizada, sustentada na problematização, que embase a relação interpessoal do aluno com o paciente, despertando-o para a importância da comunicação no seu cotidiano de forma consciente, ou seja, desenvolvendo sua competência interpessoal.

Stefanelli (1993) afirma que o profissional necessita desenvolver habilidades para apreender o significado dessas interações e estabelecer seu plano de assistência sem, contudo, utilizar receitas, regras únicas ou um manual de ações. Em seu trabalho diário o enfermeiro deve ser crítico, criativo e simples, respeitando as singularidades de cada paciente.

\section{METODOLOGIA}

Essa experiência foi desenvolvida com a participação de 20 alunos de um Curso Técnico em Enfermagem na cidade de Curitiba.

Os dados do estudo foram extraídos de todo material produzido em sala de aula incluindo as intervenções verbais dos alunos as quais foram registradas pelos docentes.

A trajetória metodológica constou de cinco etapas desenvolvidas em sala de aula, quando foram ministrados os conteúdos de comunicação, os quais denominam: processo educativo na busca dos dados. Utilizamos estratégias como estímulo para fazer aflorar as situações de vida, as quais contribuíram para estimular a criatividade dos alunos e ajudaram na problematização dos assuntos que emergiram. Para melhor compreensão da seqüência, relataremos as estratégias utilizadas, seguidas das discussões dos alunos emergidas durante o processo pedagógico.

\section{PRIMEIRA ETAPA}

Iniciamos expondo aos alunos os conteúdos e os objetivos do trabalho. Esta etapa teve por objetivo levar os alunos a problematizarem o conceito e as formas de comunicação, estimulando-os a correlacionarem seu conhecimento empírico à base teórica adotada no estudo sobre esses assuntos. Na seqüência, solicitamos que livremente se dividissem em dois grupos, denominados A e B, para facilitar e estimular a discussão entre eles. Solicitamos que cada grupo discutisse e explicitasse os conceitos do grupo a partir das seguintes questões: O que vocês entendem por comunicação? Quais as formas de comunicação que vocês conhecem? Destaquem as mais utilizadas pela enfermagem e exemplifiquem em que momento elas são utilizadas por vocês na assistência ao paciente.

Para a realização dessa primeira etapa, os alunos deveriam buscar subsídios em sua vivência diária, assim como nas situações já experienciadas em estágios anteriores de outras disciplinas. Em seguida, solicitamos a cada subgrupo que fizesse a apresentação do que havia construído; sendo que as discordâncias deveriam ser discutidas e da discussão advir um consenso entre o grande grupo.

\section{Sínteses elaboradas nos grupos}

Grupo "A"

-Comunicação: é o ato de se comunicar, através de gestos, palavras, expressões, olhares. Ligação entre pessoas.

-Formas de comunicação: verbal, visual e corporal.

-As mais utilizadas na enfermagem: passagem de plantão (escrita e verbal), observação de sinais e sintomas do paciente (visual), banho de leito (corporal) 


\begin{abstract}
Grupo "B"
-Comunicação: é o ato de expressar pensamentos e sentimentos através da fala, escrita, gestos. Saber ouvir e ser ouvido. É necessário que haja mais de uma pessoa envolvida. -Formas de comunicação: verbal, visual, tátil, auditiva.

-As mais utilizadas na enfermagem: segundo os alunos desse grupo, todas são utilizadas simultaneamente; o primeiro contato se dá através do cumprimento, quando ambos, paciente e pessoal de enfermagem, apresentam-se (verbal), observam-se (visual), realizam-se as técnicas e expressam sentimentos (tátil), um ouve o outro - escuta ativa (auditiva).
\end{abstract}

Com a apresentação de cada grupo, chegou-se ao seguinte entendimento: A comunicação é uma forma de comunicar-se que envolve mais de uma pessoa; mensagens são expressas através da fala, escrita, gestos e expressões físicas. Ela promove ligação entre pessoas e permite que um conheça o outro.

As formas de comunicação citadas por eles foram a verbal, a visual, a corporal, a tátil e a auditiva. Afirmaram que todas são muito usadas, dependendo somente da situação. A comunicação nas situações de assistência de enfermagem ocorre por meio da observação dos sinais e sintomas, do prontuário, da prescrição de enfermagem, o banho de leito, a passagem do plantão, com a equipe de enfermagem, com outros profissionais da equipe, com a instituição, com outras instituições, com a família.

Na seqüência passamos a apresentar os conceitos de comunicação humana, formas de comunicação e suas respectivas funções, elementos da comunicação e como eles atuam neste processo dinâmico, com base no conceito central do referencial de Stefanelli (1993).

\title{
SEGUNDA ETAPA
}

Para o desenvolvimento dessa etapa, solicitamos aos alunos dos grupos A e B, que criassem a dramatização de uma interação, utilizando os conhecimentos discutidos na etapa anterior, situações vivenciadas na prática de disciplinas anteriores ou alguma situação de vida em que estiveram envolvidos. As apresentações foram filmadas. Ao término das representações, fornecemos aos alunos uma lista de técnicas de comunicação terapêutica e uma de comunicação não-terapêutica. Solicitamos que lessem o material fornecido e, em seguida, enquanto a filmagem era assistida pelos grupos, pedimos que identificassem a comunicação utilizada, tanto terapêutica quanto as não-terapêutica, bem como as não abordadas na dramatização de seu grupo e na dos colegas.

$\mathrm{Na}$ dramatização, os alurtos identificaram alguns comportamentos dos visitantes, que teciam comentários inadequados ao mesmo tempo que mudavam de assunto, trazendo para a conversa situações tipo "mexericos de comadre" como comunicação não-terapêutica. No momento de discussão sobre tais comportamentos, ficou evidente que os alunos não tinham claro sobre a quem caberia a responsabilidade do uso da comunicação terapêutica. O profissional de enfermagem, protagonista de uma dramatização, esclarecia os visitantes sobre a importância do silêncio e respeito pelo paciente, apesar de seu estado de inconsciência. Também informava aos visitantes que a paciente os estava ouvindo, pois a audição é o último dos sentidos humanos que se perde.

Stefanelli (1993) afirma não ser a comunicação terapêutica restrita aos profissionais da saúde e uma ação terapêutica, segundo Silva (1996), é aquela que traz benefício ao paciente tanto quando vinda de um profissional quanto de qualquer outra pessoa, porém esclarecemos aos alunos que, na qualidade de prestadores de assistência à saúde temos o dever e a responsabilidade de desenvolver habilidades que nos permitam fazer da comunicação uma ação terapêutica. 
Procuramos nessa etapa, de uma maneira lúdica, criar um espaço que propiciasse aos alunos oportunidade para aprender a criticar e a receber críticas, levando-os a melhorar o seu senso de observação e crítica, contribuindo na lapidação de suas atitudes na relação com o outro. Os objetivos foram discutir os conteúdos de Comunicação Terapêutica, explicitando as categorias Expressão, Clarificação e Validação, e de Comunicação Não-terapêutica, segundo Stefanelli (1993). Antes, porém, pedimos aos alunos que dissessem de forma livre o que entendiam por expressão, clarificação e validação.

Nesse momento, reapresentamos o conceito dé comunicação, estabelecendo a diferença entre esta e a comunicação terapêutica.

\section{TERCEIRA ETAPA}

Nesta fase, discutimos a comunicação não-verbal. Para tanto, apresentamos o desenho animado $\mathrm{O}$ Velho Moinho, de Walt Disney (1937), no qual o autor apresenta várias cenas mímicas. Em seguida, os alunos apontaram aquelas quando os personagens demonstravam sentimentos, revendo-as sempre que surgissem dúvidas. Solicitamos que dissessem como perceberam e que citassem outras formas de comunicação não-verbal explicitadas nas cenas do desenho.

Para subsidiar esta discussão, passamos a ministrar o conteúdo de comunicação nãoverbal e alguns pressupostos de Stefanelli (1993).

\section{QUARTAETAPA}

Para que o aluno desenvolvesse seu auto-conhecimento, que é um dos principais elementos para seu aprendizado e para a compreensão de como acontece a sua comunicação com o outro, utilizamos o jogo Tangram (1991), pois consideramos que o seu uso pode reforçar a importância da comunicação na relação interpessoal, levar os participantes a fazerem introspecção para o desenvolvimento do auto-conhecimento e levá-los a entender como se dá, para cada um, o processo de comunicação com o outro, bem como identificar barreiras e ruídos que podem surgir e interferir no curso da comunicação.

Este jogo de origem chinesa, criado há mais de mil anos, é composto por sete peças geométricas: um quadrado, dois triângulos menores, um triângulo médio, dois triângulos maiores e um paralelogramo, com as quais é possível criar inúmeras figuras e modalidades de jogos. Esse jogo já foi utilizado por Maftum e Mazza (1998) em oficinas de prevenção ao uso de drogas e de doenças sexualmente transmissiveis, ainda que o foco tenha sido a comunicação entre pais e filhos adolescentes.

\section{O jogo de Tangram}

Os alunos associaram-se em duplas, e cada uma delas recebeu um jogo de Tangram (1991). Os alunos manusearam as peças para familiarizarem-se com as formas geométricas. O primeiro pedido foi que construíssem um quadrado utilizando todas as peças do jogo. $\grave{A}$ medida que cada dupla ia concluindo a tarefa, prontamente os alunos se levantavam e iam dar dicas as outras duplas, o que ajudou a estabelecer um clima de muita euforia e favoreceu o relacionamento interpessoal e grupal entre eles.

Na seqüência, convidamos um voluntário para ir à frente da classe. Ao aluno voluntário foi dado escolher uma das várias cartelas dispostas tal como um baralho. Cada uma apresentava o desenho de uma figura possível de se formar com as peças geométricas do Tangram. Tendo o aluno escolhido a cartela, sua tarefa seria conduzir as duplas à montagem da figura da cartela escolhida. O aluno que estava no comando da atividade não poderia verbalizar a palavra "não"; 
mas poderia utilizar quaisquer outros recursos que considerasse úteis para repassar instruções e ajudar os colegas a executar a tarefa, essa última informação não foi dada, a não ser que o aluno questionasse.

Se o aluno que estivesse no comando pronunciasse três vezes a palavra "não", ele perderia o comando para outro colega voluntário, que então passaria a ser o dirigente do processo. Essa ação foi repetida várias vezes quando a maioria dos alunos pôde experienciar a atividade de comando.

$\mathrm{Na}$ seqüência, foram discutido com os alunos os objetivos da técnica já explicitados anteriormente; onde emergiram as seguintes falas:

Vou pegar a carta mais fácil, para eu não errar logo; Ah! Esta eu não vou errar. O grupo fazia uma bateria de perguntas para quem estava na frente, e isso me deixava confuso.

Eu ficava muito ansiosa, queria ver o resultado logo, não tinha paciência de esperar quem estava na frente fazer as orientações, eu queria já adivinhar o que ele ia dizer.

É engraçado esse jogo, mas é difícil.

Eu falei "não"? Falei? Ih! Eu nem percebi. Dá um nervoso de não poder falar "não".

Ah! Desisto! Não vou conseguir explicar isso não.

Os colegas preferem dificultar pra quem está na frente, para ver se ele vai se dar mal e pegar o seu lugar, mas esquecem que vão fazer o mesmo que ele.

Ah! Falta coleguismo, ninguém pensa em facilitar a vida dos colegas.

Nossa! Como a gente está acostumado a dizer "não"! A gente fala e nem percebe. Fiquei muito ansiosa e com receio de aceitar, pois não conhecia todo o jogo.

Essa experiência confirmou que o jogo foi útil para que os alunos se conscientizassem de seus pontos fortes e fracos na comunicação com o outro. Igualmente demonstrou que o jogo utilizado com uma intencionalidade pedagógica, com o domínio de seu uso e com objetivos previamente estabelecidos leva a resultados eficientes no ensino-aprendizado (Maftum; Mazza, 1998), pois ocorre de forma descontraída, além de promover relação interpessoal e grupal entre os envolvidos.

O jogo propiciou, ainda, uma discussão sobre Barreiras na Comunicação. Os alunos relataram que o fato de desconhecerem todas as regras do jogo gerou insegurança e medo do desconhecido. Aproveitamos estes apontamentos para relacioná-los com a experiência de estágio dos alunos em ambiente desconhecido no hospital, assim como eles e o ambiente são desconhecidos para o paciente. Saber que tais fatores são fontes geradoras de ansiedade torna o profissional de enfermagem consciente da necessidade de direcionar suas ações e conduta de forma mais adequada.

Outro aspecto que consideramos importante foi o fato de perceber o quanto a atividade lúdica do jogo promoveu a descontração dos alunos e contribuiu melhorando a observação do processo de comunicação de cada um, tanto por meio de autocrítica como pela aceitação da crítica de colegas. Ainda nessa etapa, apresentamos os Elementos da Comunicação, segundo o referencial de Stefanelli (1993).

\section{QUINTA ETAPA}

Para a sedimentação dos conteúdos já discutidos, procedemos nesta etapa a utilização do jogo educativo "Comunicação Enfermeira e Paciente" elaborado e validado por Stefanelli (1993). Para o uso do jogo foram seguidas as regras propostas pela autora. O jogo é constituído de trinta e cinco cartas contendo mensagens sobre comunicação humana, terapêutica, relação 
interpessoal, formas, planos, modos de comunicação entre outras sobre o assunto. Distribuímos cinco cartas para cada subgrupo $A$ e $B$ e solicitamos que lessem e defendessem as idéias que havia em cada carta; caso o aluno desejasse, poderia trocar a sua carta por uma das que estavam sobre a mesa. Todos leram, fizeram a defesa das mensagens.

Para finalizar essa etapa, lançamos mão de uma lista de estratégias de comunicação terapêutica e uma de comunicação não-terapêutica, intercaladas, seguindo o mesmo referencial. Nela, os alunos deveriam identificar as estratégias de comunicação terapêutica e comunicação não-terapêutica nas respectivas colunas.

\section{CONSIDERAÇÕES FINAIS}

Essa experiência mostrou-nos uma maneira simples e concreta de ensinar comunicação em Enfermagem e reafirma os pensamentos de Mazza (1998, p. 67), é imprescindivel um repensar diário da prática, que significa perceber e demarcar a existência do que ela chama "espaços livres a serem preenchidos". Freire (1995) afirma estes apontamentos quando diz que o profissional tem o dever de "reviver" e de "renascer" a cada momento de sua prática e que, em se tratando do docente, estes atos são fundamentais para que os conteúdos que ensina sejam vivos e não noções estáticas e petrificadas.

A metodologia de ensino proposta impulsiona os alunos a serem partícipes no processo ensino aprendizagem, a partir de sua realidade vivida, desenvolvendo um espírito crítico criativo reconhecendo os problemas que de fato são relevantes. Para tanto o educador atua como facilitador da aprendizagem e de mudanças comportamentais, enfatiza sempre o aprendizado pela descoberta e, portanto, o crescimento global do ser, e alavanca o aluno a aumentar sua capacidade para atuar como agente participante da transformação social, critico e criativo, consciente da realidade em que está inserido, e capaz de ser um agente transformador da mesma (Bordenave; Pereira, 1986).

Reconhecemos que a aprendizagem ocorreu simultaneamente em duas instâncias: na primeira, em nós, docentes que ensinando o aluno a aprender, aprendíamos a fazer. Na segunda, nos alunos, sujeitos de nossa prática, que por sua vez tem no paciente a sua fonte de aprendizado e, posteriormente, o seu objeto de trabalho. Os reflexos do aprendizado do docente e do aluno que consequentemente repercutirão no paciente aconteceram pelo fato de professor e aluno, concomitantemente, compartilharem de único objetivo, que é a qualidade da assistência, que reflete diretamente no ser humano, no cidadão e na sociedade.

Pela importância que tem a comunicação na qualidade da assistência que os profissionais de saúde prestam aos pacientes, entendendo que ela é a base de todo o processo de relação interpessoal, consideramos que esse tema deva ocupar mais espaço nos currículos dos cursos de enfermagem, objetivando, desde as primeiras disciplinas, no início do curso, o preparo do aluno para interagir com o paciente.

\footnotetext{
ABSTRACT: This article reports on an experience in the teaching of communication theory to nurse technician students in Curitiba, based on the use of problem solving skills. The results ratified Stefanelli's proposition concerning the teaching-learning process of the contents about human and therapeutic communication. Therapeutic communication strategies facilitate students' understanding as well as the use of therapeutic communication in their relationship with patients. Learning was effective because teacher and students shared a common goal: the quality of nursing care.
}

KEYWORDS: communication, education, problem discussion 
RESUMEN: Se trata de relatar una experiencia de enseñanza-aprendizaje de comunicación basada en la problematización y desarrollada con alumnos del nivel Técnico en Enfermería de Curitiba. Los resultados corroboran la propuesta de Stefanelli del proceso de enseñanza-aprendizaje de los contenidos de comunicación humana y terapéutica. Las estrategias de comunicación terapéutica facilitan tanto para la comprensión de los alumnos como para la relación con el paciente. Hubo aprendizaje, justamente por el hecho de que juntos, profesor y alumno, compartieron un único objetivo, la calidad de la asistencia ao ser humano.

PALABRAS CLAVE: comunicación, educación, problematización

\section{REFERÊNCIAS BIBLIOGRÁFICAS}

BORDENAVE, J. E. D. O que é comunicação? São Paulo : Brasiliense, 1982.

BORDENAVE,J.E.; PEREIRA, A. M. Estratégias de ensino-aprendizagem. 18. ed. Petrópolis: Vozes, 1986.

FREIRE, P. A educação na cidade. São Paulo : Cortez, 1995

MAZZA, V. M. A. A comunicação não-verbal como forma de cuidado de enfermagem: ensino e prática 1998. 70p. Dissertação (Mestrado em Enfermagem) - Curso de Pós Graduação em Enfermagem, Universidade Federal de Santa Catarina, Curitiba, 1998.

MAFTUM, M. A.; MAZZA, V. A. O jogo como recurso didático-pedagógico no ensino da comunicação. Curitiba, 1998. Digitado

O VELHO MOINHO. Walt Disney. EUA: Home Vídeo, 1937. 1 fita de vídeo (10 min), 35mm, color.

SILVA, M. J. P. Comunicação tem remédio. São Paulo : Gente, 1996.

STEFANELLI, M. C. Comunicação com o paciente - teoria e ensino. São Paulo: Robe, 1993.

TANGRAM. São Paulo : Sócio Indústria e Comércio de Brinquedos Ltda. 1991. 7 peças geométricas de madeira.

TRAVELBEE, J. Intervención en enfermería psiquiatrica. Colombia: Carvajal, 1979.

Recebido em abril de 2000 Aprovado em novembro de 2000 